\section{Reaping the benefits of basic research}

Sir - The benefit of supporting basic research has been increasingly questioned in recent years. Funding agencies in Europe and elsewhere favour applied research, some even appearing to assume that basic research is a luxury that can be done without.

One important argument in favour of basic research, however, is that it consistently yields surprises that in turn are converted into products and even whole new industry sectors, and that, without such continuous innovation, the ensuing stagnation will be damaging to the health and economic strength of society. In the life sciences, the development of monoclonal antibodies and the biotechnology industry are good examples.

But how much basic research is needed to produce the occasional result that goes beyond 'knowledge expansion' and achieves 'usefulness'? The data are sparse, but could be crucial in allowing policy-makers to arrive at more informed decisions. One source of information is the practical consequences of work carried out by scientists who have received grants to do basic research.

The European Molecular Biology Organization (EMBO), which is supported by more than 20 European countries, is well placed to obtain this information, as it has an established postdoctoral fellowship programme where the awards are made solely on the scientific quality of the research proposal. A survey of the career paths of those awarded EMBO fellowships in 1984 and 1985 (see Nature 388, 416; 1997) has been extended to ask whether the research carried out during the fellowship had knowledge as its only outcome, or whether it also led to new products, or ideas for new products.

Of the 120 individuals surveyed, 80 replied, of whom $40 \%$ provided examples of practical consequences arising from their basic research. Even making the extreme assumption that the work of all the nonresponders resulted only in abstract knowledge, there were still more than $27.5 \%$ who could list practical or applied consequences of their work. The list covers all areas of biotechnology, and can be viewed at the EMBO Web site (http://www.embo.org). Seven projects gave rise to patents, and many in the 33 examples are of obvious and direct importance in biotechnology today.

Given the outcome of this survey, and the fact that projects that receive EMBO support are judged only on the quality of the science, we should perhaps reassess policies that attempt to move a significant portion of research into areas justified on the basis of their projected applied outcome. It may be more important to allow decisions on grants to focus on the quality of the research and the researcher, and to ensure that those making the decisions are leaders in the scientific community. Selecting projects because of the promised practical outcome may have the least long-term input to the industries they wish to support.

Frank Gannon

(Executive Director)

EMBO, Meyerhofstr. 1,

D-69117 Heidelberg,

Germany

e-mail:gannon@embl-heidelberg.de

\section{Teaching research skills}

Sir - The United Kingdom's experimental programme that teaches students research skills is a step in the right direction ${ }^{1}$. The experience may also serve as a model for the United States. Many American graduate schools seem to teach students skills specific to their fields of specialization, but not general principles of research methodology. It is time they considered adding such courses to their graduate programmes.

Scientific research consists of sophisticated intellectual activities that are poorly understood. Rational or logical approaches often fail, whereas irrational methods are sometimes productive. Many scientific discoveries are made by chance rather than as a result of planned research. It is frequently intuition, not rational or conscious thinking, that leads to an innovative theory. This is why many consider the methodology of research an art that cannot be taught. For the same reason, it might be difficult to come up with a method, as desired by Boryeu $\mathrm{Mao}^{2}$, that measures fruitless research activities against those that are productive.

Nevertheless, I believe that some general principles of research methodology do exist, and an introduction to such basic knowledge (logic, philosophy of science, skills of thinking and so on) can help young scientists to improve the efficiency of their research. These methods and skills are universal and can be applied to any field. For instance, the reductionist programme has been widely used in research, even though some may not know the term reductionism. It is therefore useful for researchers to understand that this approach is not appropriate for all problems in science ${ }^{3,4}$. In his timehonoured monograph ${ }^{5}$, W. I. B. Beveridge offered a vivid account of methodology for making scientific discoveries from a psychological perspective. I recommend this work to science students.

Tianhan Xue

154 Kingston Ave, Suite E,

Santa Barbara, California 93117, USA

1. Masood, E. Nature 391, 729 (1998)

2. Mao, B. Nature 391, 738 (1998).

3. The Limits of Reductionism in Biology, Ciba Symposium, Vol. 213 (Wiley, in the press).

4. Agazzi, E. (ed) The Problem of Reductionism in Science (Kluwer Academic, Dordrecht, 1991).

5. Beveridge, W. I. B. The Art of Scientific Investigation (Heinemann, London, 1961).

\section{Cancer controversy}

Sir-Alison Abbott's summary ${ }^{1}$ of the controversial cancer therapies of Luigi Di Bella accurately documents the fact that Di Bella has so far resisted efforts to have a committee of experts review his data, which raises further concerns that his combinations of a somatostatin analogue with vitamins and/or melatonin are not as effective as he claims.

The situation is more complex, however, as there is formal preclinical evidence indicating antineoplastic activity of somatostatin analogues such as octreotide and RC-160 in tumour model systems (reviewed in refs 2,3). These molecules appear to act by lowering systemic IGF-I levels (which may be relevant to cancer risk and prognosis ${ }^{4}$ ) and/or by activating specific growth inhibitory signal transduction pathways linked to specific somatostatin receptors which are expressed by neoplastic cells ${ }^{3}$. The preclinical evidence is sufficiently impressive, particularly in low tumour burden models, for both the US National Cancer Institute and the National Cancer Institute of Canada to be conducting randomized clinical trials to evaluate the activity of octreotide in the adjuvant treatment of breast cancer. A trial based at the Mayo Clinic comparing tamoxifen to the combination of tamoxifen and low dose octreotide in the treatment of advanced breast cancer showed no difference between treatment $\mathrm{arms}^{5}$.

Somatostatin analogues may or may not be shown in formal clinical trials to be useful in the treatment of specific neoplastic diseases, but it would be a mistake to use Di Bella's conduct to discredit rigorous research in this area. Michael Pollak

\section{Department of Oncology,}

Jewish General Hospital-McGill University,

Montreal, Quebec, Canada H3T 1E2

e-mail:MD49@musica.mcgill.ca

\footnotetext{
1. Abbott, A. Nature 391, 217 (1998).

2. Weckbecker, G. et al. Cancer Res. 54, 6334 (1994).

3. Pollak, M. \& Schally, A. V. Proc. Soc. Exp. Biol. Med. 217, 143 (1998).

4. Chan, J. et al. Science 279, 563 (1998).

5. Ingle, J., Kardinal, C., Suman, V., Krook, J., Pollak, M. Proc. Amer. Soc. Clin. Oncol. 16, 150 (abstr. 526).
} 